\title{
Repercussões da Parentalidade na Conjugalidade do Casal Recasado: Revelações das Madrastas
}

\author{
Cristina Ribeiro Teixeira Dantas*, Terezinha Féres-Carneiro, \\ Rebeca Nonato Machado, \& Andrea Seixas Magalhães \\ Pontifícia Universidade Católica do Rio de Janeiro
}

\begin{abstract}
RESUMO - Realizou-se uma pesquisa qualitativa com o objetivo de investigar a vivência das madrastas acerca da conjugalidade no recasamento. Participaram do estudo 16 madrastas. Os dados foram obtidos por meio de entrevistas semiestruturadas e a análise categorial foi realizada de acordo com o método de análise de conteúdo. A partir das narrativas, emergiram seis categorias de análise: lugar da madrasta na família; denominação madrasta; conjugalidade no recasamento; díade madrasta-enteado; tríade madrasta-enteado-mãe e transmissão geracional. Neste artigo, apresenta-se e discute-se a categoria conjugalidade no recasamento, desdobrada nas subcategorias conjugalidade atravessada pela parentalidade $\mathrm{e}$ repercussões da conjugalidade anterior na conjugalidade atual. Constatou-se que a construção da conjugalidade é influenciada por aspectos relativos ao exercício da parentalidade e ao relacionamento conjugal anterior.
\end{abstract}

PALAVRAS-CHAVE: madrasta; recasamento, conjugalidade, parentalidade, ex-cônjuge

\section{Repercussions of Parenthood in Marital Relations of Remarried Couples: Revelations of Stepmothers}

\begin{abstract}
A qualitative research was carried out with the objective of investigating the experience of stepmothers about conjugality in remarriage. A total of 16 stepmothers participated in the study. The data were obtained through semistructured interviews and analyzed using the content analysis method. Six categories emerged from the content analysis: the stepmother's place within the family; stepmother denomination; conjugality in remarriage; stepmother-stepchild dyad; stepmother-stepchild-mother triad; and psychic generation. This article presents and discusses the category conjugality in remarriage, unfolded in the subcategories conjugality crossed by the parenthood and repercussions of the previous conjugality in the current conjugality. It was found that the construction of conjugality is influenced by aspects related to the exercise of parenthood and to the previous conjugal relationship.
\end{abstract}

KEYWORDS: stepmother, remarriage, conjugality, parenthood, ex-spouse

A transformação histórica da instituição familiar torna difícil a elaboração de um conceito que abarque as diversas noções de família, na medida em que a mesma engloba funções afetivas, políticas, sociais, culturais e econômicas, em diferentes contextos. Entre as múltiplas configurações familiares da atualidade, pode-se destacar a família recasada, configuração constituída a partir de novo enlace conjugal após a separação conjugal de um ou ambos os sujeitos ou após a viuvez de um deles ou de ambos (Soares, 2012).

Neste artigo, a família recasada refere-se a uma nova união conjugal, após separação ou viuvez, na qual pelo menos um dos cônjuges possui filho(s) de relacionamento(s) anterior(es). Considerando aspectos como o número, o gênero, a idade e os arranjos de moradia dos filhos provenientes dos enlaces conjugais anteriores de cada cônjuge, juntamente com a possibilidade de o novo casal vir a ter filhos, observa-se o surgimento de inúmeros formatos, abarcados nessa configuração familiar.

De acordo com os dados do Instituto Brasileiro de Geografia e Estatística (IBGE, 2012), as famílias recasadas, no Brasil, que representavam $13,4 \%$ da população em 2002, subiram para 16,1\% em 2007 e, em 2012, passaram

\footnotetext{
*E-mail: c.r.dantas@hotmail.com

- Submetido: 10/11/2015; Revisado: 14/03/2016; Aceito: 09/05/2016.
} 
a representar $21,8 \%$ da população. O recasamento inicia uma nova etapa no ciclo vital dos seus integrantes, gerando mudanças nos padrões sociais e em sua dinâmica relacional, possibilitando o estabelecimento de novos vínculos (McGoldrick \& Carter, 2001; Pryor, 2014). Além disso, a inclusão de novos membros (padrasto, madrasta, irmãos socioafetivos, consanguíneos, meio-irmãos e a família extensa de cada cônjuge) aponta para a necessidade de redefinições no que tange aos papéis familiares.

Com relação aos papéis familiares na família recasada, McGoldrick e Carter (2001) ressaltam que os sujeitos passam a desempenhar múltiplos papéis sem que tenham tido tempo para se adaptar a eles. Em muitos casos, os novos cônjuges se deparam com a necessidade de exercer o papel de madrasta e de padrasto, ao mesmo tempo em que estão construindo a sua identidade conjugal. Nesse escopo, a conjugalidade é perpassada, simultaneamente, pelas demandas parentais relativas aos filhos de casamentos anteriores e por possíveis repercussões da conjugalidade anterior.

Papernow (2013) apresenta cinco desafios enfrentados pelos membros da família recasada: o sentimento de inclusão/exclusão vivenciado pela madrasta e pelo padrasto, no que diz respeito à dinâmica familiar anterior; os conflitos de lealdade vivenciados pelos filhos/enteados; as tarefas parentais polarizando o novo casal; a criação da nova identidade familiar e a inclusão do ex-cônjuge nas questões pertinentes aos filhos do casamento anterior. Essa autora afirma que a madrasta e o padrasto vivenciam sentimentos ambíguos acerca dos papéis parentais a serem desempenhados.

Hackner, Wagner e Grzybowski (2006) sugerem que a maior causa dos conflitos ocorridos após o desenlace conjugal advém da falha em estabelecer fronteiras no relacionamento que possibilitem aos ex-cônjuges serem parceiros na parentalidade, mas não na conjugalidade. Para além do rompimento conjugal, o recasamento de um ou ambos os ex-cônjuges inicia um processo de novas organizações, visando a atender as demandas advindas dos filhos nascidos do enlace conjugal anterior. Cabe ressaltar que, diferentemente dos laços intersubjetivos conjugais que são dissolúveis, os laços intersubjetivos parentais são indissolúveis (Ziviani, Féres-Carneiro, \& Magalhães, 2012).

O termo parentalidade passou a ser utilizado a partir da década de 1980, para designar o agrupamento das funções e dos papéis parentais, sendo utilizado para se referir ao processo de tornar-se pai e mãe, abarcando os aspectos conscientes e inconscientes inerentes a essa experiência (Houzel, 2004; Vidigal \& Tafuri, 2010). A conjugalidade, por sua vez, refere-se à identidade compartilhada a partir do entrelaçamento das subjetividades dos membros do casal, tendo sua origem na história familiar de cada um. Desse modo, a construção da conjugalidade é marcada pela continuidade geracional, por meio da qual os modelos parentais e conjugais da família de origem são transmitidos e modificados (Magalhães, 2009).
Embora a família contemporânea ressalte a possibilidade de cada indivíduo constituir-se como autônomo, a formação de um casal demanda a criação de uma zona de interação compartilhada por ambos. A dinâmica do casal é estabelecida entre as forças paradoxais compostas pelas individualidades dos sujeitos e por uma conjugalidade, comum a ambos, forjando o desafio de preservar a sua individualidade, concomitantemente à construção da identidade conjugal. Nesse sentido, a conjugalidade diz respeito aos planos, projetos e sonhos em comum, assim como à história que os sujeitos estão escrevendo a dois. Caberá ao casal, casado ou recasado, construir e ressignificar aspectos referentes ao seu passado e ao presente para que a convivência seja enriquecedora e satisfatória para ambos (Féres-Carneiro, 1998).

O casamento envolve um movimento contraditório, no qual os sujeitos, a despeito de se separarem, continuam se recasando, buscando, a partir dessa experiência, o estabelecimento de novos vínculos afetivos que possibilitem a vivência da intimidade. A busca pela felicidade, a possibilidade de ter uma companhia e a realização afetiva são fatores que impulsionam os sujeitos a se casarem novamente (Costa \& Dias, 2012).

Em relação à conjugalidade, pesquisas sugerem o acréscimo de interesse, no âmbito acadêmico, por temas como aspectos conceituais, conflitos e interações conjugais, influência da conjugalidade na parentalidade, satisfação conjugal, dissolução da conjugalidade, entre outros (FéresCarneiro \& Diniz Neto, 2010; Lucier-Greer \& Adler-Baeder, 2011; Robertson \& Ehrenberg, 2012; Silva, Trindade, \& Silva Junior, 2012; Ziviani et. al., 2012). Contudo, Ganong, Coleman e Jamison (2011) apontam para a lacuna expressiva em pesquisas acerca do processo de desenvolvimento dos relacionamentos na família recasada, ressaltando a necessidade de pesquisas sobre as díades pai/madrasta e mãe/padrasto. Assim, compreender o modo como os ajustes pertinentes ao subsistema conjugal repercutem no subsistema parental e vice-versa pode trazer importantes contribuições acerca dos papéis a serem desempenhados nessa configuração familiar.

A partir dessas considerações, a inserção da madrasta na família recasada suscita redefinições acerca das fronteiras dos subsistemas familiares, assim como possíveis renegociações dos papéis parentais. Costa e Dias (2012) pontuam que o recasamento requer melhor delimitação de fronteiras, uma vez que vários níveis de ajustamento de subsistemas - conjugal, parental, fraterno - ocorrem ao mesmo tempo, exigindo flexibilidade e criatividade dos sujeitos para lidar com as diversas demandas.

A conjugalidade, no recasamento, além de ser perpassada por questões referentes à parentalidade, convoca a uma reflexão acerca das expectativas no que diz respeito ao papel da madrasta. Ao mesmo tempo em que estão construindo a sua identidade conjugal, as madrastas necessitam de tempo para se adaptar às 
mudanças na rotina. No âmago dessas considerações, o presente trabalho tem como objetivo investigar, a partir da perspectiva das madrastas, a vivência do atravessamento da parentalidade e das possíveis repercussões que a dissolução da conjugalidade anterior exerceriam sobre a conjugalidade atual.

\section{MÉTODO}

\section{Participantes}

Participaram deste estudo 16 madrastas, com idades variando entre 28 e 43 anos, residentes na cidade do Rio de Janeiro e pertencentes às camadas médias da população.

Partimos da definição de camadas médias como algo mais abrangente e complexo do que classe social, considerando as semelhanças entre os indivíduos desse grupo (Velho, 1987). Das 16 madrastas, dez residem com, pelo menos, um enteado; três passam pelo menos um dia da semana com os enteados, revezando os finais de semana e três encontram com os enteados nos finais de semana a cada 15 dias. A Tabela 1 apresenta a descrição do perfil das participantes.

\section{Instrumentos e Procedimentos}

Como instrumento de investigação, foi utilizada a entrevista semiestruturada. As entrevistas foram gravadas em áudio e, posteriormente, transcritas integralmente. $\mathrm{O}$ roteiro, composto por questões abertas, foi formulado a partir da revisão da literatura acerca do tema e contemplou os seguintes eixos temáticos: construção do lugar da madrasta; o imaginário social acerca da madrasta; vivência da conjugalidade no recasamento; construção do relacionamento com os enteados; relacionamento com as mães dos seus enteados. As entrevistas tiveram a duração de uma a três horas e o local, data e horário foram agendados de acordo com a disponibilidade das madrastas. $\mathrm{O}$ acesso às participantes ocorreu por meio de indicações, configurando, portanto, uma amostra de conveniência.

\section{Cuidados Éticos}

O projeto de pesquisa foi aprovado pelo Comitê de Ética da instituição em que foi desenvolvido. Todas as participantes assinaram o Termo de Consentimento Livre e Esclarecido, autorizando a divulgação dos resultados em ensino, pesquisa e publicação e foram informadas de que a sua identidade e a de seus familiares seriam preservadas.

\section{Análise dos Dados}

Os dados coletados foram submetidos ao método de análise de conteúdo, na sua vertente categorial, com a finalidade de investigar, a partir do material discursivo, as

Tabela 1

Características biográficas das madrastas entrevistadas

\begin{tabular}{|c|c|c|c|c|c|c|}
\hline \multirow[t]{2}{*}{ Madrasta } & \multirow[t]{2}{*}{ Idade } & \multirow[t]{2}{*}{$\begin{array}{c}\text { Tempo de recasamento } \\
\text { (em anos) }\end{array}$} & \multicolumn{2}{|c|}{ Enteado } & \multicolumn{2}{|c|}{ Filho } \\
\hline & & & Número & Idade & Número & Idade \\
\hline M1 & 34 & 8 & 1 & 17 & 1 & 1 \\
\hline M2 & 43 & 7 & 1 & 11 & 1 & 3 \\
\hline M3 & 43 & 3 & 3 & $27 ; 20 ; 15$ & 2 & $11 ; 3$ \\
\hline M4 & 39 & 6 & 1 & 13 & 2 & $5 ; 3$ \\
\hline M5 & 28 & 9 & 1 & 12 & - & - \\
\hline M6 & 40 & 2 & 5 & $\begin{array}{c}31 ; 30 ; 16 \\
15 ; 9\end{array}$ & - & - \\
\hline M7 & 36 & 2 & 1 & 13 & 1 & 1 \\
\hline M8 & 38 & 3 & 1 & 12 & - & - \\
\hline M9 & 28 & 6 & 2 & $16 ; 10$ & 1 & 1 \\
\hline M10 & 38 & 14 & 2 & $24 ; 15$ & 1 & 11 \\
\hline M11 & 41 & 8 & 2 & $16 ; 11$ & - & - \\
\hline M12 & 31 & 5 & 1 & 15 & 1 & 1 \\
\hline M13 & 37 & 6 & 2 & $17 ; 15$ & 1 & 2 \\
\hline M14 & 39 & 7 & 1 & 17 & 1 & 2 \\
\hline M15 & 37 & 11 & 1 & 12 & - & - \\
\hline M16 & 35 & 4 & 1 & 7 & 1 & 1 \\
\hline
\end{tabular}


significações atribuídas pelas entrevistadas aos fenômenos (Bardin, 2011). Por meio da técnica categorial, foram destacadas categorias temáticas, organizadas a partir da semelhança entre os elementos contidos no material coletado. Para tal, procedeu-se a uma "leitura flutuante", agrupando-se dados significativos, identificando-os e relacionando-os, até se destacarem as categorias de análise.

O presente trabalho apresenta parte dos resultados de pesquisa ampla, cujo objetivo foi investigar as dimensões da conjugalidade e da parentalidade no recasamento, a partir da vivência das madrastas. Nessa investigação mais ampla, das narrativas das participantes emergiram seis categorias de análise: lugar da madrasta na família; denominação madrasta; conjugalidade no recasamento; díade madrastaenteado; tríade madrasta-enteado-mãe e transmissão geracional. Para apresentação e discussão neste trabalho, destaca-se a categoria conjugalidade no recasamento e suas subcategorias conjugalidade atravessada pela parentalidade e repercussões da conjugalidade anterior na conjugalidade atual. Assim, o objetivo deste artigo é investigar, a partir da perspectiva das madrastas, a vivência do atravessamento da parentalidade e as possíveis repercussões que a dissolução da conjugalidade anterior exerceria sobre a conjugalidade atual.

\section{RESULTADOS E DISCUSSÃO}

Para apresentação dos resultados, as madrastas foram nomeadas de um a 16 , colocando-se, em seguida, a idade de cada uma.

\section{Conjugalidade no Recasamento}

Compreendendo a conjugalidade como um processo de construção de uma realidade comum ao casal, no qual as atitudes de um cônjuge influenciam e são influenciadas pelo outro, observa-se, no recasamento, a necessidade de o novo casal negociar as distintas demandas relativas à parentalidade e à conjugalidade anterior. Dessa forma, esta categoria explicita as interferências sofridas pelo novo casal, concomitantemente à construção da sua identidade conjugal.

\section{Conjugalidade Atravessada pela Parentalidade}

Enquanto constroem a sua identidade conjugal, o novo casal se depara com o desafio de manejar satisfatoriamente os investimentos afetivos nas dimensões conjugais e parentais. Observa-se, no recasamento, a constituição de vínculos forjados na interação entre sujeitos entrelaçados por diversas famílias (McGoldrick \& Carter, 2001), tornando fundamental a investigação acerca da constituição da conjugalidade nas díades madrasta-pai e padrasto-mãe, perpassada pela parentalidade.

Ao serem questionadas sobre a sua relação conjugal, as madrastas ressaltam a complexidade do interjogo estabelecido entre as dimensões conjugais e parentais. A conquista do seu lugar, a necessidade de negociar espaços distintos que abarquem as demandas conjugais e parentais, lidar com a frustração e conseguir processar os próprios sentimentos de ciúmes e dos enteados surgem como desafios vivenciados pelas madrastas no momento em que constituíam a sua identidade conjugal:

Também tiveram vários momentos tensos, tipo fim de semana que a gente tava com a W. (enteada), eu fazia uma proposta do tipo 'vamos pro clube?'... Ao invés do D. (marido) emitir a opinião dele, ele perguntava se a $W$. queria ir... Ele passava essa autoridade pra ela e, obviamente, nesse momento de ameaça de lugar, ela dizia 'não'. Eu tive várias conversas com o D. dizendo: 'olha, eu acho que existe o espaço dos três, existe o meu espaço com o D. e existe o espaço dele com a W., são três espaços distintos. (madrasta 2, 43 anos)

Pra mim também era complicado, então eram dois lados sentindo cada um ciúme na dimensão, né?... Ela tinha cinco e eu 31... Eu passava por coisas tipo 'ai, que saco, eu queria ficar só eu e ele'... Qual vai ser o meu espaço nessa relação? No fundo você tá disputando uma mulher com outro homem, mas são dois amores diferentes. (madrasta 4, 39 anos)

A gente ficou um ano só pro casal. A introdução das crianças veio aos poucos...Teve o periodo que a gente se mudou e ficou em função da casa e das crianças e eu ficava muito cansada. Misturava cansaço com a frustração...Até tinha tempo para o casal, mas eu achava que não era suficiente. Depois eu relaxei e parei de brigar com isso...Isso durou uns dois anos. (madrasta 11, 41 anos)

A partir das narrativas, observa-se a necessidade de ajustes vivenciados pelas madrastas em suas dinâmicas relacionais. Sentir ciúmes, lidar com a frustração, processar os diversos afetos, adaptar-se a diferentes demandas, negociar com seus cônjuges aspectos referentes ao exercício dos papéis, além de estabelecer espaços discriminados para as vivências da conjugalidade e da parentalidade, sugerem a complexidade experimentada nessas configurações familiares.

Enquanto constituem a identidade conjugal, as madrastas manejam seus anseios, expectativas, frustrações, inseguranças e idealizações, no âmbito da parentalidade, uma vez que o exercício das funções parentais pode ser expandido, abarcando, além dos laços consanguíneos, os laços socioafetivos. A ambiguidade entre fazer parte e se sentir excluída de uma dinâmica que a precede aponta para a importância de permanentes negociações entre as madrastas e seus cônjuges. O possível sentimento de inclusão/exclusão das madrastas, no que se refere às funções parentais, pode 
suscitar conflitos e readaptações. Além disso, o modo como a mesma é inserida pelo marido no contexto familiar recasado é fundamental para a sua aceitação, ou não, por parte dos enteados (Papernow, 2013; Pryor, 2014; Soares, 2008).

O recasamento inicia uma nova família, todavia, ao invés de o relacionamento amoroso acontecer de forma progressiva, do namoro ao casamento e, posteriormente, o nascimento dos filhos, os sujeitos passam a desempenhar múltiplos papéis. No ciclo vital da família recasada, diversos relacionamentos são inaugurados ao mesmo tempo em que o casal está constituindo a sua identidade conjugal. Nesse escopo, o novo casal não dispõe de privacidade para adaptar-se à vivência conjugal, uma vez que os filhos, de um ou de ambos, já existem e demandam atenção e cuidados (McGoldrick \& Carter, 2001; Papernow, 2013). As narrativas das madrastas mencionam suas experiências referentes ao convívio com seus próprios filhos e enteados:

Ele foi morar com a gente quando a gente casou. Eu voltei da lua de mel e ele tava na minha casa... Uma coisa que me marcou foi que a assistente falou assim: 'E você, tá preparada pra ter uma criança em casa? Você tá preparada pra sair do banho e não poder andar pelada em casa? E você querer transar com o seu marido no sofá e não poder?' Ai eu: 'não tinha pensado nisso' (risos)...Eu perdi a privacidade que era tão sonhada. (madrasta 5, 28 anos)

Às vezes fica muito conturbado porque começa a girar tudo em função deles (filho e enteado)...Hoje a gente consegue sair porque ficam os dois juntos em casa, um de 15 e um de 11 ... Ai então a gente consegue ter momentos só nossos agora... A gente não teve uma rede de apoio, então durante muito tempo era tudo em função deles, então teve um momento que ficou chato o casamento, mas agora a gente tá saindo pra se divertir, viajar sozinhos, então tá bom. (madrasta 10, 38 anos)

A limitação da privacidade, seja pela entrada dos enteados ou pelo nascimento de um filho, altera a dinâmica do casal, pois acrescenta a dimensão da parentalidade à conjugalidade (Papernow, 2013). Vale ressaltar que, das 16 madrastas entrevistadas, dez residem com, pelo menos, um enteado e, entre as outras seis, somente uma não possui filho (madrasta 11). Embora os dados do IBGE (2012) afirmem que, após o desenlace conjugal, $87,1 \%$ das mães obtiveram a guarda dos filhos, o presente estudo constata um número maior de homens residindo com sua prole. Nesse sentido, a despeito da diversidade de contextos, os homens almejam envolvimento afetivo e participação na vida dos filhos (Warpechowski \& Mosmann, 2012).

Nesse contexto, o cotidiano é modificado para acolher as crianças e, em algumas situações, o casal passa a adaptar as demandas conjugais conforme as necessidades dos filhos/ enteados. Certamente, as demandas relativas ao exercício da parentalidade precisam ser atendidas, todavia, quando o casal não consegue espaço para constituir a sua identidade conjugal, as dimensões da conjugalidade e da parentalidade podem permanecer indiscriminadas. Ademais, a excessiva idealização acerca das funções parentais e conjugais, no recasamento, possibilita que sejam projetadas no novo parceiro expectativas não cumpridas no âmbito dessas duas dimensões (Magalhães, Féres-Carneiro, Henriques, \& Travassos-Rodriguez, 2013). Em contrapartida, a manutenção de fronteiras nítidas entre os subsistemas conjugal e parental pode assegurar que os filhos/enteados não se sobrecarreguem com questões conjugais, ao mesmo tempo em que preservam o espaço relativo à conjugalidade (Wagner, Tronco, \& Armani, 2011).

Conforme se pode perceber, a disponibilidade da madrasta em acolher os filhos do marido como integrantes significativos da família pode trazer contribuições ao casal conjugal. O manejo satisfatório do investimento afetivo nos novos vínculos familiares favorece tanto a conjugalidade, quanto a parentalidade. Em contrapartida, o superinvestimento afetivo em uma dimensão pode sugerir escassez em outra.

A aceitação dos adultos, no que tange aos arranjos de moradia dos filhos e enteados, assim como o respeito pelas responsabilidades parentais que o cônjuge tem com os filhos de casamentos anteriores, juntamente com a flexibilidade em torno dos papéis de gênero, são medidas que contribuem para relacionamentos saudáveis (McGoldrick \& Carter, 2001; Pryor, 2014). No que tange aos papéis de gênero, a maioria das madrastas relata sentir sobrecarga ao conciliar o trabalho, os enteados, os filhos e a organização da rotina da casa.

Sou eu que resolvo as coisas da casa, compra de mês, coisas da casa, tudo...É que o M. (marido) fez isso também, ele entregou, ele disse: 'tá aqui'. Ele tirou o time de campo. Quando eu entrei, eu assumi tudo...Eu administro tudo. (madrasta 6, 40 anos)

Ele (marido) não me cobrava que eu o ajudasse, mas eu não conseguia ficar sentada, vendo televisão, de braços cruzados, com as crianças em casa. Não tinha a menor condição. Ajudar no banho, enquanto o outro tá esquentando o jantar, catar os brinquedos... (madrasta 11, 41 anos)

Eu me sinto sobrecarregada, porque eu fico com o B. (filho do recasamento) até a hora dele ir pro colégio, aí, a partir do momento que ele vai pro colégio, eu posso trabalhar, fazer compras, marcar médico...É bem corrido...É uma situação muito complicada, porque o marido ganha muito mais do que a mulher na maioria das casas brasileiras, ai a mulher dá retaguarda pra ele trabalhar e botar dinheiro...Ao mesmo tempo, ela não consegue se dedicar mais ao trabalho dela e, por isso, não ganha mais, entendeu? (madrasta 13, 37 anos)

Convocadas pelos maridos e por si mesmas, as madrastas assumem a responsabilidade de gerir o lar, cuidar dos filhos e enteados, além de manter os compromissos profissionais. Conciliar a carreira, a administração da casa e a rotina das crianças parece ser um dos maiores desafios enfrentados pelas mulheres na atualidade, estejam elas em um primeiro casamento ou em um recasamento. 
Algumas madrastas sugerem a manutenção dos papéis tradicionais de gênero, em que os homens são os provedores e as mulheres se incumbem de cuidar dos filhos e da casa. Em contrapartida, Silva et al., (2012), ao realizarem pesquisa acerca das representações sociais sobre a conjugalidade no recasamento, postulam a tendência de relacionamentos conjugais mais igualitários. Esses dados apontam para a convivência, na contemporaneidade, de relacionamentos tanto pautados em dinâmicas que priorizam os papéis tradicionais de gênero, quanto em relacionamentos nos quais os papéis exercidos pelos sujeitos podem ser flexíveis e cambiáveis (Féres-Carneiro \& Ziviani, 2009). A coexistência de configurações mais tradicionais ou mais modernas deflagra a necessidade do convívio com o diferente (Wagner \& Levandowski, 2008).

Convém destacar que, das 16 madrastas entrevistadas, 15 estavam trabalhando e, entre elas, 12 possuem pósgraduação. Os dados do IBGE (2010) acerca do nível de instrução afirmam que a população feminina superou a masculina nesse quesito. Enquanto 9,9\% dos homens possuem curso de graduação, as mulheres representam $12,5 \%$. O maior investimento feminino na vida profissional está transformando os valores acerca do papel da mulher e, consequentemente, alterando as relações entre os gêneros.

Os diversos papéis assumidos pelas mulheres - mãe/ madrasta, dona de casa e profissional - implicam em uma maior participação do pai na criação dos filhos/enteados e nos afazeres domésticos. A inserção da mulher no mercado de trabalho originou mudanças nas famílias e nas relações de gênero, convocando o pai a ocupar um lugar mais participativo na interação familiar (Jablonski, 2009; RochaCoutinho, 2015). Articulando as demandas conjugais com as parentais, algumas madrastas afirmam admirar o modo como seus maridos exercem a função parental:

Você tem que amar muito e ter muita vontade de construir uma família com ele...Não foi fácil... Ele falou pra mim: 'eu não vou desistir da minha filha' porque a I. (mãe) fez tudo pra ele desistir da $V$. (enteada), porque ela queria construir pra filha uma imagem como se o pai tivesse abandonado ela. O fato dele não ter desistido me fez ver a capacidade paterna dele. Eu admiro muito isso nele. (madrasta 14, 39 anos)

Imerso na teia de interações familiares, o "novo pai" encontra-se efetivamente mais envolvido na vida de seus filhos (Souza \& Benetti, 2009). Assim, a capacidade do marido em continuar engajado no exercício das funções parentais é percebida pelas madrastas como um aspecto positivo, sendo motivo de admiração. Percebe-se que o investimento no exercício das funções parentais pode repercutir de maneira positiva na conjugalidade do novo casal, uma vez que o marido se sente legitimado pela sua esposa a manter as responsabilidades parentais e o vínculo com seus filhos, possibilitando que os investimentos afetivos nas dimensões conjugais e parentais adquiram um caráter dinâmico.
A necessidade de elaborar as vivências, processar as emoções e negociar as diferenças com seus cônjuges também aparece nas falas das madrastas. Algumas afirmam que não teriam mantido o recasamento sem a sua psicoterapia individual, a do enteado ou a do casal:

Eu nunca pensei que não iria assumir essa história por causa dos filhos...Eu to feliz, mas eu entrei aqui e levei muita porrada, então eu to me reestruturando. Eu e o M. (marido) estamos fazendo uma terapia juntos pra saber como lidar com as crianças. (madrasta 6, 40 anos)

Eu posso dizer que se não fosse o meu espaço de análise pra poder falar disso e não despejar no casamento, eu não sei se eu teria dado conta... Às vezes é isso, você tá transbordando de emoções ali e um destempero, você despeja em cima da pessoa e ela não entende, não sabe nem o que você tá falando. Eu tenho a certeza de que ele (marido) não tem ideia do que aconteceu comigo. (madrasta 11, 41 anos)

A V. (enteada) foi pra terapia com seis pra sete anos, então, quando a gente casou, ela tinha uns nove pra dez e ai ela conseguiu levar essas alianças...Eu convidei ela pra levar, foi muito trabalhado na análise dela...Ela faz análise desde a separação dos pais...Eu acho que a nossa vida, eu não sei como teria sido. Eu fazendo análise, ela e ele (marido). Eagora a mãe da V. também. (madrasta 14, 39 anos)

Os relatos preconizam o espaço terapêutico como um local privilegiado para elaboração das mudanças pessoais e relacionais vivenciadas no recasamento. Identificar a dinâmica conjugal, entrando em contato com os anseios, expectativas, idealizações, frustrações, entre outros aspectos, pode favorecer a promoção da saúde emocional dos sujeitos envolvidos no recasamento.

No âmbito da conjugalidade, pesquisas apontam a comunicação como um aspecto fundamental para o bom relacionamento do casal. Desentendimentos gerados pela perda de controle das emoções, pela falta de comunicação e pelo medo de se expor podem desencadear conflitos conjugais (Papernow, 2013; Tadeu da Silva, 2012; Wagner, Falcke \& Mosmann, 2015).

\section{Repercussões da Conjugalidade Anterior na Conjugalidade Atual}

A constituição da conjugalidade, no recasamento, para além de ser perpassada pelas vicissitudes da parentalidade, também sofre influências advindas da conjugalidade anterior. Nesse contexto, o modo como o desenlace conjugal anterior ocorreu e o processo vivenciado entre a separação e o recasamento repercutem na dinâmica conjugal do novo casal.

A partir das narrativas das madrastas, pode-se perceber que o relacionamento dos seus maridos com suas exmulheres, juntamente com as vivências relativas à elaboração do processo de luto da separação anterior, perpassam o 
relacionamento atual, influenciando, por conseguinte, a interação conjugal no recasamento.

A primeira (ex-mulher), a mãe do $H$. (enteado), frequenta a minha casa, mas com a segunda (ex-mulher) é um pouco mais delicado. Quando o P. (marido) casou com a primeira mulher, ele sabia que não ia ficar com ela, então não era um projeto de vida junto e o segundo casamento era um projeto de vida junto que não deu certo, então foi muito mais doloroso, foi muito mais frustrante, um luto muito maior. Eu acho que deixou marcas muito mais profundas. (madrasta 3, 43 anos)

No atual momento que nós nos casamos, agora a vítima é ela (mãe). Ela se coloca para os filhos nessa situação. Existe uma campanha contra mim...Não é sem sofrimento...Nessa dinâmica, que não é $100 \%$, eu tento fazer com que isso não afete a minha relação. (madrasta 6, 40 anos)

Eu falava pro O. (marido): 'o problema não é você ter dois filhos, o problema é você ter duas ex-mulheres'. E aí tinha aquela coisa de não trocar o fim de semana... No início ela tava toda rígida nos horários e eu dando plantão, às vezes queria viajar no fim de semana, tava com eles e ai a gente tinha que ficar...Eu tinha que organizar tudo pra quando eu não estivesse de plantão ou quando eu não estivesse com as crianças, então isso foi o mais complicado. (madrasta 10, 38 anos)

Não é o ideal pra mim. Não éo que eu sonhava. Eu achava que ia ser mais fácil e às vezes eu sinto que atrapalhou um pouco (a vida do casal). Eu, às vezes, eu tenho um pouco de inveja das mulheres que casaram com homens que não tinham uma história anterior, mas eu aprendi muito. (madrasta 14, 39 anos)

As falas sugerem a interferência da ex-esposa em diversos fatores na vida do casal. A flexibilidade em modificar a rotina para acomodar as necessidades parentais e o respeito ao período de luto do casamento anterior vivenciado pelo cônjuge são maneiras encontradas pelas madrastas para apoiar seus maridos. O conceito de qualidade conjugal seria o resultado de um processo dinâmico e relacional acerca do nível de qualidade experimentado naquela união, considerando as dimensões contextuais, os recursos pessoais e os processos adaptativos (Mosmann, Wagner, \& Féres-Carneiro, 2006). Dessa forma, a qualidade conjugal estaria ligada à capacidade dos sujeitos em lidar com as diferenças, superar os momentos de crise e se readaptar às novas situações e demandas, conjugais e parentais.

Os maridos, por sua vez, podem preservar as madrastas dos possíveis impactos advindos da conjugalidade anterior. Assim como o "novo pai" foi adquirindo novas funções no que diz respeito à parentalidade, o "novo marido" deve investir na demarcação das fronteiras entre a conjugalidade atual e a parentalidade exercida com sua ex-esposa. Conforme se pode perceber, caso o luto pelo casamento anterior não seja elaborado, o marido pode incluir a atual mulher e a ex-mulher em uma triangulação (Bowen, 1991), compreendendo uma díade e um terceiro, que será convocado a participar quando o nível de desconforto e de ansiedade aumentar entre as duas pessoas. A entrada do terceiro surge para aliviar a tensão na díade.

McGoldrick e Carter (2001) afirmam existir, no recasamento, uma bagagem emocional composta pela família de origem, pelo primeiro casamento, pelo processo de separação conjugal e pelo período entre os casamentos. Segundo essas autoras, a bagagem emocional pode gerar conflitos e sofrimento psíquico quando os sujeitos se sentem vulneráveis a novas mágoas ou quando esperam que o novo relacionamento atenue o sofrimento e as dificuldades vivenciadas no relacionamento anterior. Em contrapartida, quando cada cônjuge consegue elaborar e transformar as suas próprias questões emocionais, o recasamento pode seguir seu curso de maneira satisfatória (Papernow, 2013).

Até as separações mais desejadas podem gerar sentimentos de perda, solidão, vazio e tristeza, que são característicos do período pós-divórcio, necessitando de tempo para serem elaborados e transformados. Quando o processo de separação possibilita o amadurecimento emocional e a reconstrução da identidade individual, os ex-cônjuges podem entrar em novos relacionamentos com menos pendências dos relacionamentos anteriores. Da mesma forma, passada a crise inicial, o processo pode contribuir para a resiliência de todos os envolvidos (Papernow, 2013, Wagner \& Féres-Carneiro, 2000). Compartilhar as funções com o cônjuge, cuidar das bagagens emocionais próprias e do outro, juntamente com o manejo dos investimentos afetivos referentes ao casal e aos filhos/ enteados podem ser fatores construtores e consolidadores da conjugalidade no recasamento.

Entre as 16 madrastas, sete relatam que a separação do marido no casamento anterior ocorreu de modo consensual. Em três casos, as mulheres solicitaram a separação e em seis relatos os homens o fizeram. Convém ressaltar, nas narrativas das madrastas, a rapidez com que os homens se recasaram.

Três meses depois eu fui morar com ele. Ai ela (ex-mulher) achava que eu tava grávida...Ela ficou achando que a gente teve algum caso antes e não teve nada, mas foi um prazo muito curto, então eu acho que ela pode ter falado mal de mim pro D. (enteado). (madrasta 10, 38 anos)

Eu conheci, tinha cerca de um mês que ele tava morando na casa de um amigo...A gente engrenou muito rápido, então eu acho que essa separação, pra ele, já, aliás, ele tava fazendo análise pra fazer a separação. Pra ex-mulher, já nem tanto, porque, ao longo do tempo, a gente foi vendo algumas dificuldades...Eu posso dizer que a gente tá juntos há dez anos e tem cerca de dois anos que a convivência tá amigável... Antes era civilizada, mas melhor não encontrar, entendeu? (madrasta 11, 41 anos)

O começo foi bem difícil, foi coisa de novela, recadinho, telefonema pra me xingar ...ele (marido) que quis se separar. Como foi muito rápido, ficou aquela coisa no ar de que a gente já tava juntos antes e não tava. (madrasta 13, 37 anos) 
A rapidez dos homens em se recasar corrobora dados de outras pesquisas que afirmam que os homens têm mais dificuldade do que as mulheres em ficar sozinhos, buscando, no recasamento, a constituição de uma nova família (Féres-Carneiro, 2003; Silva et. al., 2012). A pressa que pode levar os homens a formarem uma nova família pode estar relacionada à dificuldade de elaboração do luto referente ao casamento anterior, influenciando na relação do novo casal. Dentro do panorama de desenlace conjugal e recasamento, um dos grandes desafios vivenciados na separação e, posteriormente, no recasamento, é a dificuldade em discriminar os aspectos referentes à dissolução da conjugalidade e à manutenção dos papéis parentais.

\section{CONSIDERAÇÕES FINAIS}

O recasamento surge como possibilidade de nova vinculação, permitindo que a intimidade, a afetividade e o companheirismo possam ser vivenciados. Essa configuração compreende o entrelaçamento de várias famílias, apontando para a necessidade de permanentes negociações acerca das fronteiras, da privacidade, do espaço, entre outros aspectos. A complexidade e as expectativas acerca dos papéis parentais podem gerar sofrimento e conflitos, dificultando a discriminação entre os subsistemas conjugais e parentais. Porém, essa complexidade pode contribuir para a criação de relacionamentos pautados na flexibilidade, possibilitando que as experiências compartilhadas adquiram caráter singular e engendrem o sentimento de pertencimento.

Observa-se que as madrastas se deparam com inúmeros desafios ao conciliar as vivências individuais, profissionais, o relacionamento conjugal e o exercício das funções parentais com filhos e enteados. Apesar do questionamento acerca da tradicional divisão dos papéis de gênero, de acordo com os dados encontrados, ainda prevalece a ideia de que caberia à mulher, fundamentalmente, os cuidados com a prole e a casa. Na linha dessas considerações, atrelar, majoritariamente, à natureza feminina os cuidados, no âmbito privado, contribui para o sentimento de sobrecarga da mulher, haja vista que a mesma participa, tal como seu cônjuge, da esfera pública.

A história do casamento anterior, assim como as lembranças passadas boas ou ruins, estará sempre ligada à presença dos filhos desse casamento. Aspectos referentes ao modo como o casamento anterior acabou, o modo como o casamento atual começou e o período existente entre a separação e o recasamento são constitutivos da conjugalidade nessa configuração familiar. Esse contexto coloca o tempo passado em um tempo presente, no qual as memórias não são partilhadas por todos os integrantes da família. Entretanto, novas memórias podem ser criadas e memórias passadas processadas ao longo do tempo, forjando a construção da identidade familiar. Lidar com o processo de luto referente ao casamento anterior do cônjuge, com as reorganizações cotidianas e com os possíveis embates entre o cônjuge e sua ex-esposa, foram alguns desafios elencados pelas madrastas. No cerne dessas considerações, a carga de afetos relativos ao fracasso do projeto de vida do casamento anterior pode ser projetada nas madrastas, repercutindo no relacionamento conjugal atual.

Percebe-se, nas narrativas das madrastas, a necessidade de elaborar as expectativas, frustrações, fantasias, receios e idealizações construídas ao longo do recasamento. A capacidade de a família recasada construir uma nova identidade familiar, abarcando suas diversas tonalidades e contrastes, está relacionada à possibilidade de elaboração desses estados emocionais. Nesse sentido, o fato de muitas madrastas buscarem psicoterapia leva a pensar que estariam buscando novas maneiras de se comunicar com seus maridos e enteados, além de procurar entender suas escolhas e vivências, vislumbrando, assim, novas formas de conciliar aspectos individuais, conjugais e parentais.

Constata-se que uma das medidas promotoras de saúde emocional está relacionada ao fato de a madrasta apoiar o marido nas questões referentes aos cuidados com os filhos de casamentos anteriores, assim como de tentar compreender as possíveis interferências que esses podem vir a exercer sobre o casamento atual. Em relação ao marido, há uma expectativa sobre a compreensão acerca das possíveis repercussões do seu relacionamento anterior no atual, a fim de que possa filtrar a quantidade e a intensidade das interferências que perpassariam o seu recasamento. Ao diferenciar os papéis parentais dos conjugais, o novo casal favorece o interjogo entre essas duas dimensões e, por conseguinte, preserva a conjugalidade.

Os vínculos que se criam dentro da família recasada representam importante fonte de material de estudo, que podem trazer conhecimento acerca dos relacionamentos e suas repercussões na família. Constata-se a importância da realização de novas pesquisas que investiguem as nuances da conjugalidade e da parentalidade, a divisão das funções entre os atuais cônjuges e ex-cônjuges, os relacionamentos nas díades madrasta-pai e padrasto-mãe, visando a um aprofundamento sobre a promoção de saúde emocional nessa configuração familiar. 


\section{REFERÊNCIAS}

Bardin, L. (2011). Análise de conteúdo. São Paulo: Edições 70. Bowen, M. (1991). De la familia ao individuo. Barcelona: Paidós. Costa, J. M., \& Dias, C. M. S. B. (2012). Famílias recasadas: Mudanças, desafios e potencialidades. Psicologia: Teoria e Pesquisa, 14(3), 72-87.

Féres-Carneiro, T. (1998). Casamento contemporâneo: O difícil convívio da individualidade com a conjugalidade. Psicologia: Reflexão e Crítica, 11(2), 379-394.

Féres-Carneiro, T. (2003). Separação: O doloroso processo da dissolução da conjugalidade. Estudos de Psicologia, Natal, 8(3), 367-374.

Féres-Carneiro, T., \& Diniz Neto, O. (2010). Construção e dissolução da conjugalidade: Padrões relacionais. Paidéia, 20(46), 269-278.

Féres-Carneiro, T., \& Ziviani, C. (2009). Conjugalidades contemporâneas: Um estudo sobre os múltiplos arranjos amorosos da atualidade. In T. Féres-Carneiro (Org.), Casal e família: Permanências e rupturas (pp. 83-107). São Paulo: Casa do Psicólogo.

Ganong, L. H., Coleman, M., \& Jamison, T. (2011). Patterns of stepchild-stepparent relationship development. Journal of Marriage and Family, 73, 396-413. doi:10.1111/j.17413737.2010.00814.x

Hackner, I., Wagner, A., \& Grzybowski, L. S. (2006). A manutenção da parentalidade frente à ruptura da conjugalidade. Pensando Famílias, 10(2), 73-86.

Houzel, D. (2004). As implicações da parentalidade. In L. SolisPonton (Org.), Ser pai, ser mãe, parentalidade: Um desafio para o terceiro milênio (pp. 47-51). São Paulo: Casa do Psicólogo.

IBGE (2012). Estatística do registro civil. Recuperado de http://www. ibge.gov.br/home/estatística/populacao/registrocivil/2012/ default.shtm.

IBGE (2010). Estatística do registro civil. Recuperado de http://www. ibge.gov.br/home/estatística/populacao/registrocivil/2012/ default.shtm.

Jablonski, B. (2009). Atitudes e expectativas de jovens solteiros frente à família e ao casamento: duas décadas de estudos. In T. Féres-Carneiro (Org.), Casal e família: Permanências e rupturas (pp. 109-134). São Paulo: Casa do Psicólogo.

Lucier-Greer, M., \& Adler-Baeder, F. (2011). An examination of gender role attitude change patterns among continuously married, divorced, and remarried individuals. Journal of Divorce \& Remarriage, 52, 225-243. doi:10.1080/1050255 6.2011.556977.

Magalhães, A. S., Féres-Carneiro, T. Henriques, C. R., \& TravassosRodriguez, F. (2013). O lugar do padrasto na clínica com famílias recasadas. In T. Féres-Carneiro (Org.), Casal e família: Transmissão, conflito e violência (pp. 113-140). São Paulo: Casa do Psicólogo.

Magalhães, A. S. (2009). Conjugalidade e parentalidade na clínica com famílias. In T. Féres-Carneiro (Org.), Casal e família: Permanencias e rupturas (pp. 205-217). São Paulo: Casa do Psicólogo.

McGoldrick, M., \& Carter, B. (2001). Constituindo uma família recasada. In M. McGoldrick, \& B. Carter (Orgs.), As mudanças do ciclo de vida familiar. Uma estrutura para a terapia familiar (pp. 95-105). Porto Alegre: Artes Médicas.
Mosmann, C., Wagner, A., \& Féres-Carneiro, T. (2006). Qualidade conjugal: Mapeando conceitos. Paidéia, 16 (35), 315-325.

Papernow, P. L. (2013). Surviving and thriving in stepfamily relationships - What works and what doesn't. New York: Routledge.

Pryor, J. (2014). Stepfamilies: A global perspective on research, policy and practice. New York: Routledge.

Rocha-Coutinho, M. L. (2015). Investimento da mulher no mercado de trabalho: repercussões na família e nas relações de gênero. In T. Féres-Carneiro (Org.), Família e casal: Parentalidade e filiação em diferentes contextos (pp. 103-117). Rio de Janeiro: Editora PUC.

Robertson, M., \& Ehrenberg, M. F. (2012). Remarried parents and views on marital commitment: Expanding the context of influences and changes. Journal of Divorce \& Remarriage, 53, 368-385. doi: 10.1080/10502556.2012.682879.

Silva, P. O. M., Trindade, Z. A., \& Silva Junior, A. (2012). As representações sociais da conjugalidade entre casais recasados. Estudos de Psicologia, 17(3), 435-443.

Soares, L. C. E. C. (2008). A família com padrasto e/ou madrasta: Um panorama. In L. M. T. Brito (Org.), Família e separações: Perspectivas da psicologia jurídica (pp. 81-112). Rio de Janeiro: Editora UERJ.

Soares, L. C. E. C. (2012). "Você não é meu pai!" - Atribuições de padrastos e madrastas em famílias recasadas após separação conjugal. Estudos e Pesquisas em Psicologia, 12(1), 319-326.

Souza, C. L. C., \& Benetti, S. P. C. (2009). Paternidade contemporânea: Levantamento da produção acadêmica no período de 2000 a 2007. Paidéia, 19(42), 97-106.

Tadeu da Silva, P. S. (2012). Percepção da conjugalidade por casados e recasados. A inelutável comparação (Dissertação de Mestrado em Psicologia Clínica). Universidade de Coimbra, Portugal.

Velho, G. (1987). Individualismo e cultura. Rio de Janeiro: Jorge Zahar.

Vidigal, M. M. B. A., \& Tafuri, M. A. (2010) Parentalização: Uma questão psicológica. Latin American Journal of Fundamental Psychopathology Online, 7(2), 65-74.

Wagner, A., Falcke, D., \& Mosmann, C. P. (2015). Viver a dois: (ma proposta de intervenção psicoeducativa na conjugalidade. In T. Féres-Carneiro, (Org.). Família e casal: Parentalidade e filiação em diferentes contextos (pp. 149-163). Rio de Janeiro: Editora PUC.

Wagner, A., \& Féres-Carneiro, T. (2000). O recasamento e a representação gráfica da família. Temas em Psicologia, 8(1), 11-19.

Wagner, A., \& Levandowski, D. C. (2008). Sentir-se bem em família: Um desafio frente à diversidade. Revista Textos \& Contextos, Porto Alegre, 7(1), 88-97.

Wagner, A., Tronco, C., \& Armani, A. B. (2011). Os desafios da família contemporânea: revisitando conceitos. In A. Wagner (Org.), Desafios psicossociais da família contemporânea (pp. 19-35). Porto Alegre: Artmed.

Warpechowski, A., \& Mosmann, C. (2012). A experiência da paternidade frente à separação conjugal: Sentimentos e percepções. Temas em Psicologia, 20(1), 247-260.

Ziviani, C., Féres-Carneiro, T., \& Magalhães, A. S. (2012). Pai e mãe na conjugalidade: Aspectos conceituais e validação de construto. Paideia, 22(52), 165-175. doi: 10.1590/S0103863X2012000200003. 